DOI: https://doi.org/10.47405/mjssh.v6i4.727

\begin{tabular}{|c|c|}
\hline & Malaysian Journal of Social Sciences and Humanities (MJSSH) \\
\hline Malaysian Journal of & Volume 6, Issue 4, April 2021 \\
\hline (MJ-sSH) & e-ISSN : 2504-8562 \\
\hline & $\begin{array}{l}\text { Journal home page: } \\
\text { www.msocialsciences.com }\end{array}$ \\
\hline
\end{tabular}

\title{
Penyuntingan Hasil Terjemahan e-Translasi Arab-Melayu: Analisis Pandangan Pengamal Penterjemahan melalui Protokol Pemikiran Verbal (Think-Aloud Protocols)
}

\author{
Lubna Abd Rahman', Arnida A.Bakar', Nurhasma Muhamad Saad1 \\ 1Fakulti Pengajian Bahasa Utama, Universiti Sains Islam Malaysia (USIM) \\ Correspondence: Lubna Abd Rahman (lubna@usim.edu.my)
}

\begin{abstract}
Abstrak
E-Translasi atau terjemahan mesin merupakan salah satu teknologi yang diguna pakai oleh penterjemah dalam menghasilkan terjemahan pantas. Penggunaan e-Translasi dianggap penting untuk digunapakai seiring dengan arus globalisasi ini yang memerlukan akses kepada informasi secara cepat dan efektif, di samping memudahkan proses terjemahan. Namun, e-Translasi tidak semestinya menghasilkan output berkualiti tinggi kerana penterjemahannya dilakukan secara kata demi kata atau literal. E-Translasi tidak dapat menandingi kepakaran manusia dalam menghasilkan terjemahan yang berkualiti. Oleh itu, penterjemah perlu melalui proses penyuntingan hasil e-Translasi untuk menghasilkan teks sasaran yang lebih baik. Lazimnya dalam proses penyuntingan penterjemah akan mempunyai kesukaran kerana hasil e-Translasi lebih bersifat literal. Kajian ini bertujuan mengetengahkan pandangan pengamal penterjemahan atau penterjemah terhadap masalah dan cadangan penyelesaian dalam isu penyuntingan teks yang diterjemahkan melalui salah satu aplikasi eTranslasi, iaitu Google Translate (GT). Kajian ini berbentuk kualitatif dan mengguna pakai kaedah Protokol Pemikiran Verbal (Think-aloud Protocols-TAPs) secara restrospektif, yang bertujuan menyingkap apa yang terdapat di dalam minda penterjemah semasa proses penyuntingan dilakukan. Berdasarkan dapatan kajian, penulis merumuskan bahawa terdapat empat aspek utama yang perlu diberi perhatian semasa proses penyuntingan terhadap hasil terjemahan e-Translasi dilakukan oleh penterjemah iaitu: perkataan dan frasa, struktur ayat, teks dan tatabahasa. Hal ini kerana GT ada kalanya tidak dapat menghasilkan padanan atau terjemahan yang menepati sistem dan struktur bahasa sasaran ekoran perbezaan linguistik dan budaya antara bahasa sumber (BSu) dengan bahasa sasaran (BSa), serta kekurangan dalam sistem terjemahan GT itu sendiri yang lebih bersifat literal. Semua aspek tersebut harus diberi perhatian secara menyeluruh apabila melakukan penyuntingan terhadap hasil terjemahan e-Translasi untuk mengelakkan kekeliruan atau ketaksaan dalam memahami mesej sebenar teks sumber.
\end{abstract}

Kata kunci: penyuntingan, e-Translasi, penterjemahan, Protokol Pemikiran Verbal (Think-aloud Protocols)

\section{Editing an Arabic-Malay e-Translation Product: An Analysis on the Translators' Perceptions via Think-aloud Protocols}

\author{
Abstract
}


E-Translation or machine translation is one of the technologies used by translators in producing fast translations. The use of e-Translation is considered important in line with the age of globalization that requires quick and effective access to information, in addition to facilitating the translation process. However, e-Translation does not necessarily produce high quality output as it occasionally translates text literally. E-Translation could not compete with human expertise in producing quality translations. Thus, translators need to go through the process of editing the product of e-Translation to produce better target text. Generally, the translator will have difficulties in the editing process as the product tend to be more literal. This study aims to highlight the perceptions of translation practitioners or translators on the problems and proposed solutions in the issue of editing texts that were translated through one of the e-Translation applications, namely Google Translate (GT). This study adopted qualitative approach and utilized the method of Think-Aloud Protocols (TAPs) retrospectively, which aims to reveal what is in the mind of the translators during the editing process. Based on the findings of the study, it was found that there are four main aspects that need to be considered during the editing process of e-Translation product, namely: words and phrases, sentence structure, text and grammar. This is because the GT is unable to produce equivalent translations that are acceptable in the target language system and structure due to linguistic and cultural differences between the source language and the target language. Moreover, the GT translation system itself tend to translate the text literally in some instances. All these aspects should be given thorough attention when editing the e-Translation product to avoid confusion or inaccuracy in understanding the actual message of the source text.

Keywords: editing, e-Translation, translation, Think-aloud Protocols

\section{Pengenalan}

Terjemahan inter-lingual merupakan bentuk pemindahan mesej yang melibatkan dua bahasa, yang pertama Bahasa sumber (BSu) dan kedua Bahasa sasaran (BSa). Proses pemindahan mesej ini ada kalanya agak sukar ditangani kerana perbezaan yang wujud antara kedua-dua Bahasa tersebut terutamanya daripada aspek linguistik dan budaya. Sering kali penterjemah akan menghadapi kesukaran untuk mencari padanan yang sesuai untuk mewujudkan kesepadanan (equivalence) antara kedua-dua teks. Tetapi, tugas penterjemahan bukan terhenti sekadar itu sahaja. Hasil terjemahan seharusnya akan melalui proses penyuntingan bagi tujuan menilai kualiti terjemahan yang dihasilkan dan seterusnya memurnikannya (Wan Rose, 2013), lebih-lebih lagi jika teks itu diterjemah menggunakan medium e-translasi atau mesin terjemahan bahasa seperti Google Translate (GT).

Seiring dengan kepesatan teknologi pada masa kini, e-translasi atau mesin terjemahan digunakan secara meluas sebagai salah satu peralatan asas dalam proses terjemahan, di samping penggunaan kamus bercetak yang masih menjadi rujukan utama penterjemah. Peralatan seumpama ini merupakan satu kemudahan yang mempercepatkan proses terjemahan, tambahan pula sesetengah e-Translasi boleh dicapai secara percuma dan mudah didapati. Oleh itu e-translasi dilihat sebagai medium penterjemahan yang banyak memberi manfaat kepada para penterjemah dalam tugasan mereka. Google Translate sebagai contoh ialah salah satu e-translasi yang paling banyak digunakan di seluruh pelosok dunia kerana menawarkan khidmat terjemahan teks lebih daripada 50 bahasa (Nur Faezah, 2015).

Walau bagaimanapun, e-Translasi masih tidak dapat menandingi kepakaran manusia dalam menghasilkan terjemahan yang berkualiti kerana sistem bahasa yang rumit dan banyak bergantung kepada pelbagai faktor, antaranya budaya, konteks dan ciri-ciri linguistik bahasa itu sendiri (Wan Rose, 2013). E-Translasi terbatas kepada perisian, perkataan dan korpus bahasa yang sedia ada tanpa mengambil kira aspek bahasa. Oleh itu, terdapat hasil terjemahan yang masih berbentuk literal dan perlu kepada pengubahsuaian dan pemurnian.

Terjemahan yang dihasilkan oleh mesin terjemahan cenderung untuk mempunyai kesalahan dari segi leksikal, tatabahasa, sintaktik, stilistik, retorik dan pragmatik. Jadi, satu proses penyuntingan bagi penambahbaikan sesebuah teks yang telah diterjemahkan menggunakan sistem mesin terjemahan perlu 
dilakukan. Di sinilah perlunya peranan penterjemah untuk menstrukturkan semula susunan dan olahan hasil e-Translasi melalui proses penyuntingan bagi menambah baik kualiti terjemahan dan menjamin mutu hasil terjemahan. Proses penyuntingan ini melibatkan semakan terhadap hasil e-Translasi dari aspek ketepatan pemilihan leksikal, struktur ayat, gaya bahasa dan lain-lain.

Selain itu, penterjemahan e-Translasi bukan sahaja berhadapan dengan cabaran linguistik dan budaya, malahan isu pragmatik turut menjadi perhatian utama (Nord, 1997/2001). Hal ini kerana pragmatik ada kaitan dengan penggunaan bahasa oleh penutur dengan berdasarkan kepada ujaran dan konteks dalam satu situasi pertuturan. Manakala penterjemahan pula berperanan memindahkan makna pragmatik tersebut supaya difahami dengan berkesan kepada pembaca teks sasar. Ini sudah tentu sukar bagi eTranslasi untuk mengenal pasti perbezaan serta memindahkan maksud yang dikehendaki apabila berhadapan dengan makna pragmatik antara teks sumber dan teks sasar. Oleh itu, bagi tujuan memurnikan penterjemahan e-Translasi, maka usaha mengaplikasikan pemikiran secara verbal (thinkaloud) boleh diguna pakai agar proses penyuntingan menjadi lebih teratur serta menghasilkan kualiti teks terjemahan yang lebih baik.

Proses penyuntingan ini melibatkan kognitif penterjemah semasa menyunting tugasan terjemahan. Protokol Pemikiran Verbal (PPV) atau Think-Aloud Protocols (TAPs) ${ }^{1}$ ialah kaedah yang sesuai untuk diguna pakai bagi mengetahui apa yang berlaku di minda seorang penterjemah ketika proses penyuntingan dilakukan. Oleh itu, penulisan ini cuba menyingkap pandangan pengamal penterjemahan atau penterjemah bertujuan untuk meninjau masalah yang berkisar dalam isu penyuntingan hasil terjemahan yang dilakukan melalui Google Translate (GT) serta mengetengahkan cadangan penyelesaian terhadap isu ini berdasarkan pengalaman mereka sendiri.

\section{Sorotan Literatur}

Terjemahan ialah proses kerja pemindahan maklumat daripada bahasa sumber kepada bahasa sasaran (Goh, 2013). Proses terjemahan melibatkan teks sumber dan teks sasaran dan melalui peringkat atau tahap tertentu seperti analisis, pengalihan dan penstrukturan semula (Nida \& Taber, 1969).

Rajah 1 berikut adalah berkenaan proses terjemahan yang biasanya dilalui oleh seseorang penterjemah atau penterjemahan manusia.

Rajah 1: Model Proses Terjemahan

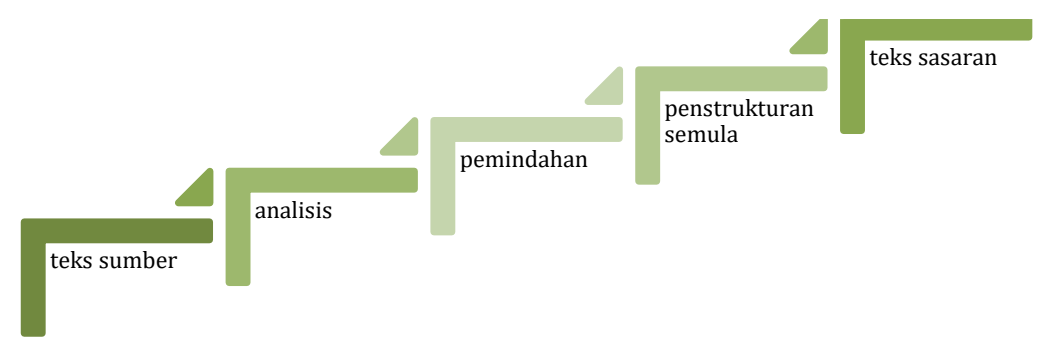

Sumber: Nida \& Taber (1969)

Model proses terjemahan yang ditunjukkan dalam rajah di atas selalunya digunakan apabila melibatkan terjemahan manusia. Penterjemah tersebut mestilah mempunyai kemahiran dalam menganalisis serta memindahkan idea atau maklumat daripada bahasa sumber (BSu) kepada bahasa sasaran (BSu). Bagaimanapun, sekiranya penterjemah menggunakan e-Translasi, proses pemindahan akan dilakukan oleh aplikasi e-Translasi yang dipilih, manakala proses analisis tidak berlaku di pihak penterjemah. Penterjemah hanya perlu melalui proses penstrukturan semula atau penyuntingan terhadap hasil e-Translasi seperti yang ditunjukkan dalam Rajah 2 di bawah:

${ }^{1}$ Penulis akan menggunakan singkatan istilah bahasa Inggeris iaitu TAPs sepanjang penulisan memandangkan istilah ini lebih dikenali dan digunakan secara meluas. 
Rajah 2: Proses E-Translasi

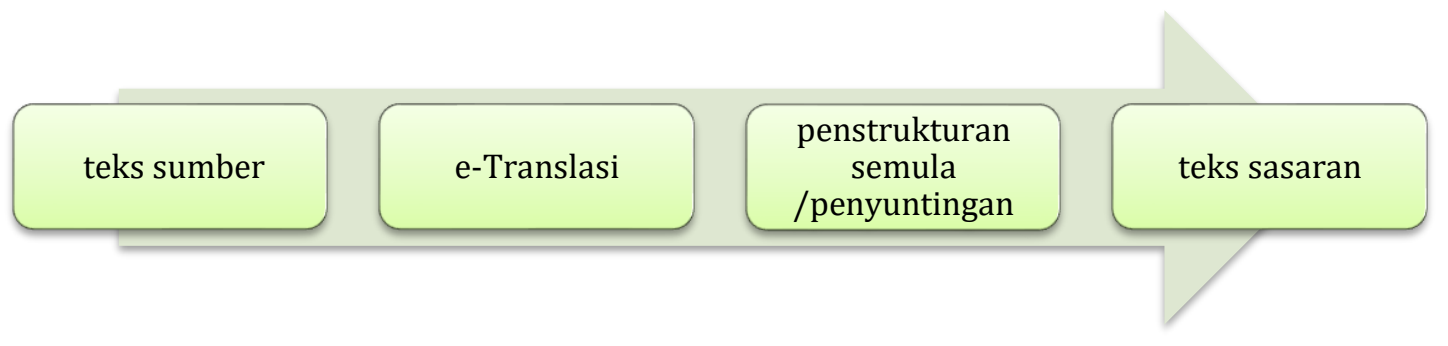

E-Translasi dalam konteks ini bermaksud penterjemahan mesin (MT) iaitu dengan menggunakan aplikasi terjemahan atas talian semasa melakukan proses terjemahan. e-Translasi berfungsi dengan cara menggunakan pelbagai jenis perisian komputer bagi menghasilkan kerja terjemahan secara automatik. Apabila dilihat kepada isu tersebut, pada hakikatnya penggunaan e-Translasi atau terjemahan mesin perlu diambil kira dalam proses penterjemahan sama ada terjemahan itu berjaya atau sebaliknya (Radiah \& Wan Rose, 2008 dalam Khadijah \& Maheram, 2013).

Terjemahan yang dilakukan oleh e-Translasi seratus peratus tidak semestinya menghasilkan output berkualiti tinggi. Hal ini kerana cara mesin melakukan terjemahan adalah secara literal dan hanya sesuai dengan keadaan teks yang konteks bahasanya terhad dan bersifat teknikal. Sistem bahasa yang sangat rumit dan halus juga menjadi faktor kepada kekurangan e-Translasi dalam menjamin mutu terjemahan yang baik. Oleh itu, penyuntingan adalah sangat penting untuk mendapatkan terjemahan yang baik dan pastinya tugas ini memerlukan kepakaran manusia. (Wan Rose, 2013).

Kajian-kajian lepas mengenai e-Translasi atau penterjemahan mesin lebih menjurus kepada kajian produk atau teks sasaran yang melibatkan ketepatan makna hasil terjemahan dari aspek semantik, morfologi dan sintaksis serta perbandingan antara penterjemahan manusia dengan penterjemahan mesin. Kajian terhadap proses penyuntingan dan penstrukturan semula hasil e-Translasi seperti masalah penterjemah dalam menangani hasil e-Translasi dan tatacara serta pendekatan dalam proses penyuntingan hasil tersebut jarang sekali dibincangkan. Justeru kajian ini cuba mengkaji masalah dan pendekatan penterjemah semasa proses penyuntingan hasil terjemahan mesin ini melalui TAPs sebagai satu metode untuk mengumpulkan maklumat berkaitan.

TAPs merupakan satu kaedah yang selalunya digunapakai dalam mengkaji isu pembelajaran bahasa khususnya dalam pembelajaran bahasa kedua atau bahasa asing. Melalui TAPs, subjek akan menterjemah pemikiran, perasaan dan pendapat mereka secara verbal, ketika mereka berinteraksi dengan bahan tugasan yang disediakan (Zaleha, 2004). Kaedah ini turut diaplikasikan oleh penyelidik dalam bidang terjemahan sejak awal kurun ke-20 kerana terjemahan berkait rapat dengan bahasa. TAPs diguna pakai sebagai satu wasilah untuk mengakses minda penterjemah dalam mengenal pasti strategi yang digunakan atau masalah yang dihadapi semasa proses terjemah sedang berlaku (Bernardini, 2001). Menurut Eftekhary dan Aminizadeh (2012) pula, kajian tentang pembinaan serta proses minda secara umumnya dan proses terjemahan secara khususnya telah menjadi fokus penyelidikan sejak tiga dekad lalu. Proses kognitif manusia, khususnya dalam terjemahan boleh dikaji dalam pelbagai cara seperti memantau tindak balas terhadap rangsangan dan menganalisis kesalahan dan hasil tugasan.

Analisis Protokol Pemikiran Verbal atau Think-Aloud Protocols Analysis dalam bidang pengajian terjemahan telah bermula di Eropah pada lewat tahun 1980-an. Persoalan yang dibangkitkan adalah apa sebenarnya yang berlaku apabila seseorang melakukan aktiviti menterjemah. Analisa ini melibatkan proses ketika menterjemah, dan tidak melibatkan produk atau hasil terjemahan. Apa yang berlegar di dalam kotak fikiran seorang penterjemah (otak dikiaskan seperti black box) ketika proses menterjemah suatu teks dijadikan asas kajian atau analisa bagi protokol pemikiran verbal. Melalui analisa ini, satu penjelasan dan pendekatan dapat dicapai bagi mengetahui proses yang terlibat ketika terjemahan dibuat (Kussmaul \& Tirkkonen-Condit, 1995). 
Pelbagai usaha dan percubaan telah dibuat bagi mengetahui apa yang berlaku di minda seorang penterjemah ketika proses terjemahan suatu teks dilakukan, begitu juga kejayaan yang dicapai hasil dari usaha tersebut. Sebagai contoh, mendapatkan kepastian daripada seorang penterjemah tentang proses mental yang berlaku seperti persepsi, idea dan imaginasi yang terlibat ketika melakukan tugasan terjemahan. Proses ini menggunakan metode TAPs, yang lazimnya diaplikasikan dalam kajian terjemahan dan berasal daripada sains kognitif iaitu kajian berkaitan memahami sifat semula jadi fikiran manusia. Tujuan utama TAPs adalah bagi mengenal pasti apa yang berlaku dalam pemikiran seorang penterjemah ketika melakukan tugasan terjemahan dan ini melibatkan proses terjemahan dan tidak meliputi produk terjemahan (Bernardini, 2001).

Selain itu, pemikiran secara verbal (thinking aloud) menerangkan mengenai kaji diri atau introspeksi. Kaedah ini melibatkan pendekatan dalaman iaitu meninjau penterjemahan sebagai proses dengan memfokuskan kepada apa yang berlegar di fikiran penterjemah ketika aktiviti menterjemah berlaku. Hasil mendapati wujud sejenis monolog dalaman yang dikemukakan oleh penterjemah itu sendiri. Selain itu, peninjauan mengenai proses penterjemahan oleh penterjemah boleh dibuat apabila mereka selesai menterjemah menerusi pertanyaan seperti kesulitan yang dihadapi, ketidaktentuan dalam memilih leksikal dan keterbatasan dalam menyelesaikan tugasan menterjemah (Widdowson, 2013). Satu laporan secara lisan atau (verbal reports) yang juga dipanggil sebagai Protokol Pemikiran secara Verbal (Think-Aloud Protocols) diperolehi daripada penterjemah dan kemudiannya dirakam dan ditranskripsikan bagi tujuan pengrekodan dan analisis. Ini merupakan satu cara bagi mengetahui apa yang berlaku dalam fikiran penterjemah ketika proses penterjemahan berlaku.

\section{Metod Kajian}

Kajian ini berbentuk kualitatif, bertujuan menyelidik pandangan penterjemah terhadap teks bahasa Arab yang diterjemahkan ke bahasa Melayu menggunakan medium e-translasi. Dalam kajian ini, aplikasi Google Translate (GT) digunakan sebagai medium untuk menghasilkan teks terjemahan e-Translasi, memandangkan aplikasi ini mudah diakses dan paling banyak digunakan dalam kalangan pelajar untuk melakukan proses penterjemahan.

Kajian ini secara khususnya mengguna pakai kaedah Protokol Pemikiran Verbal atau lebih dikenali dengan Think-Aloud Protocols (TAPs). TAPs melibatkan perkaitan antara pengujaran dengan proses kognitif yang sedang berlaku, iaitu dengan menterjemahkan pemikiran bukan verbal dalam bentuk verbal. Terdapat dua bentuk kaedah bagaimana pemikiran verbal dan proses kognitif dalam TAPs berlaku, iaitu secara serentak (concurrent) dan kedua retrospektif. Dalam kaedah TAPs secara serentak, proses pemikiran berlaku seiring dengan pengujaran semasa subjek berinteraksi dengan tugasan yang diberikan. Oleh itu, maklumat yang diberikan adalah secara langsung dan menurut urutan pemikiran. Manakala dalam kaedah retrospektif pula, proses kognitif mengambil masa serta melibatkan usaha untuk memahami dan memperoleh maklumat daripada tugasan dan pengujaran akan dilakukan selepas itu (Ericsson \& Simon, 1993).

Dalam kajian ini, kaedah TAPs dilakukan secara retrospektif melalui beberapa prosedur yang bertujuan mendapatkan maklumat seperti berikut:

i. Subjek kajian diberikan tugasan berbentuk teks yang diterjemahkan daripada bahasa Melayu ke bahasa Arab melalui Google Translate (GT).

ii. Subjek diberikan tempoh masa selama dua minggu untuk meneliti hasil e-Translasi ArabMelayu

iii. Temu bual dijalankan bersama dengan subjek kajian dan hasil perbualan dirakam. Soalan temu bual bentuk terbuka diajukan dengan memfokuskan dua persoalan utama iaitu masalah yang dihadapi semasa menyunting tugasan teks terjemahan dan strategi atau tatacara terjemahan yang boleh diaplikasikan untuk mengatasi masalah tersebut.

iv. Data yang diperoleh ditranskripsikan dan dirumuskan (seperti dalam hasil kajian di bawah)

Seramai lima orang subjek kajian atau responden telah dipilih untuk menyertai kajian ini, terdiri daripada penterjemah yang mempunyai pengalaman menterjemah antara 5 hingga 12 tahun. Selain itu, 
pandangan dua orang pakar rujuk dalam bidang Terjemahan Arab-Melayu turut diambil semasa membincangkan tajuk kajian dalam Diskusi Meja Bulat (RTD) bagi menyokong dan mengesahkan data yang diperoleh, selain mendapatkan input tambahan berkaitan aspek tumpuan dalam proses penyuntingan hasil e-Translasi.

\section{Hasil Kajian}

Hasil kajian ini dibahagikan kepada dua fokus utama, iaitu: Isu terjemahan hasil e-Translasi ArabMelayu dan cadangan penyelesaian terhadap masalah hasil e-Translasi semasa penyuntingan. Pandangan pakar terhadap penyuntingan e-Translasi Arab-Melayu juga akan dirumuskan.

Isu yang dimaksudkan di sini merujuk kepada masalah yang dihadapi semasa subjek kajian menyunting tugasan teks terjemahan. Manakala cadangan penyelesaian pula merujuk kepada strategi yang dilakukan atau dicadangkan oleh subjek kajian terhadap masalah yang diutarakan semasa menyunting hasil eTranslasi.

Jadual 1 menunjukkan bahawa terdapat beberapa aspek tumpuan yang mempunyai masalah dalam proses penyuntingan serta cadangan penyelesaian yang diutarakan oleh subjek kajian. Antaranya perkataan atau frasa, tatabahasa, struktur ayat, gaya Bahasa, perkataan budaya dan kohesi atau koheren teks.

Jadual 1: Rumusan Masalah Yang Dihadapi Dan Cadangan Penyelesaian

\begin{tabular}{|c|c|c|}
\hline Tema Isu & Perincian Isu & Cadangan Penyelesaian \\
\hline Perkataan & $\begin{array}{l}\text { - Pemilihan perkataan atau } \\
\text { terminologi yang tidak tepat dan } \\
\text { tidak sesuai mengikut konteks } \\
\text { bahasa sumber. } \\
\text { - Percampuran bahasa dalam teks } \\
\text { terjemahan Google Translate } \\
\text { yang tidak dapat } \\
\text { menterjemahkan beberapa } \\
\text { perkataan ke dalam bahasa } \\
\text { sasaran (Bahasa Melayu) tetapi } \\
\text { diterjemahkan pula ke bahasa } \\
\text { lain (Bahasa Inggeris dan } \\
\text { Bahasa Indonesia. } \\
\text { - Berlaku pengulangan perkataan } \\
\text { yang sama dalam satu frasa. }\end{array}$ & $\begin{array}{l}\text { - Kenal pasti konteks yang melatari } \\
\text { ayat dan seterusnya memilh } \\
\text { perkataan yang tepat dan sesuai } \\
\text { dengan konteks ayat. } \\
\text { - Membuat carian makna perkataan } \\
\text { di internet atau kamus dengan } \\
\text { melihat konteks makna yang } \\
\text { sesuai selain melihat bagaimana } \\
\text { terminologi tersebut digunakan } \\
\text { dalam kalangan orang arab. } \\
\text { - Terjemahan perlu disemak } \\
\text { dengan teliti agar perkataan yang } \\
\text { dipilih tepat dengan konteks } \\
\text { bahasa sasaran. } \\
\text { Menganalisis teks sumber untuk } \\
\text { mengetahui dan memahami isi } \\
\text { kandungan teks tersebut. }\end{array}$ \\
\hline Tatabahasa & 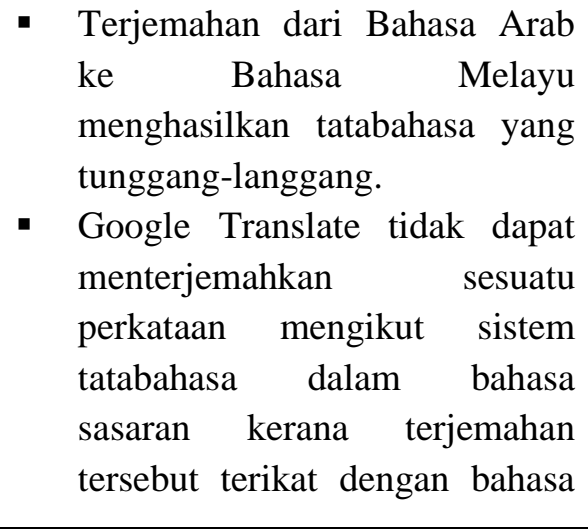 & $\begin{array}{l}\text { - } \text { Mulakan terjemahan } \\
\text { menggunakan terjemahan ayat } \\
\text { yang menggunakan tatabahasa } \\
\text { asas yang kemudiannya } \\
\text { ditambahbaik secara berperingkat } \\
\text { bagi mengelakkan kesalahan } \\
\text { terjemahan ayat kompleks yang } \\
\text { menggunakan tatabahasa yang } \\
\text { lebih kompleks. } \\
\text { Penterjemah perlu mengaplikasi } \\
\text { dan mematuhi sistem tatabahasa } \\
\text { bahasa sasaran dalam terjemahan }\end{array}$ \\
\hline
\end{tabular}


DOI: https://doi.org/10.47405/mjssh.v6i4.727

\begin{tabular}{|c|c|c|}
\hline & $\begin{array}{l}\text { sumber dan diterjemahkan } \\
\text { secara literal. } \\
\text { - Kesalahan dari segi terjemahan } \\
\text { kata kerja aktif dan pasif }\end{array}$ & $\begin{array}{l}\text { dan tidak terikat dengan sistem } \\
\text { tatabahasa bahasa sumber yang } \\
\text { sememangnya berbeza dengan } \\
\text { bahasa sasaran. } \\
\text { Masalah tatabahasa di Google } \\
\text { Translate perlu diatasi dengan } \\
\text { pengetahuan mendalam } \\
\text { penterjemah terhadap tatabahasa } \\
\text { bahasa sasaran. } \\
\text { Analisis hubungan tatabahasa } \\
\text { iaitu kata-kata yang membawa } \\
\text { mesej dan makna seperti } \\
\text { ungkapan lisan, istilah ungkapan } \\
\text { yang menjadi norma bahasa } \\
\text { sasaran untuk menghasilkan } \\
\text { makna linguistik, makna rujukan } \\
\text { dan makna emosi } \\
\text { Rujuk sumber yang dipercayai } \\
\text { dalam menyemak tatabahasa teks } \\
\text { seperti: } \\
\text { http://prpm.dbp.gov.my/ } \\
\text { https://www.almaany.com/ } \\
\text { https://www.oxfordlearnersdictio } \\
\text { naries.com/ }\end{array}$ \\
\hline $\begin{array}{c}\text { Struktur } \\
\text { Ayat }\end{array}$ & $\begin{array}{l}\text { - Kebanyakan ayat dalam teks } \\
\text { sumber panjang-panjang dan } \\
\text { dihubungkan dengan kata } \\
\text { hubung 'dan' yang } \\
\text { menyebabkan pengulangan } \\
\text { 'dan' terlalu kerap dalam satu } \\
\text { ayat yang sama dalam teks } \\
\text { sasaran. } \\
\text { - Terdapat juga ayat yang } \\
\text { tergantung kerana terjemahan } \\
\text { dilakukan secara literal ataupun } \\
\text { tidak diterjemahkan secara } \\
\text { lengkap. } \\
\text { - Struktur ayat terjemahan kaku } \\
\text { dan tidak hidup. } \\
\text { - Struktur ayat kurang tepat. }\end{array}$ & 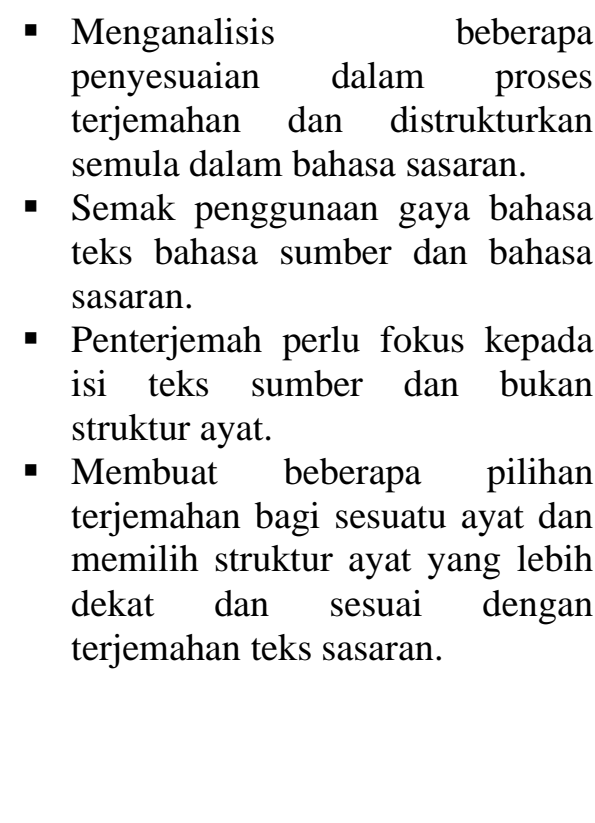 \\
\hline Gaya Bahasa & $\begin{array}{l}\text { Keindahan gaya bahasa teks } \\
\text { terjemahan tidak dapat } \\
\text { ditonjolkan dengan baik kerana } \\
\text { terdapat banyak padanan } \\
\text { perkataan yang kurang tepat, } \\
\text { kesalahan tatabahasa dan juga } \\
\text { struktur ayat yang terlalu terikat } \\
\text { dengan bahasa sumber. } \\
\text { - Gaya bahasa yang kompleks } \\
\text { yang menyukarkan proses } \\
\text { pemahaman pembaca sasar. }\end{array}$ & $\begin{array}{l}\text { - Membuat semakan di internet } \\
\text { bagi melihat penggunaan gaya } \\
\text { bahasa teks sasaran dari } \\
\text { perspektif pembaca, penutur dan } \\
\text { pengguna bahasa sasaran. } \\
\text { - Semak makna padanan yang } \\
\text { dibekalkan. } \\
\text { - Melakukan bacaan yang berulang } \\
\text { dan meneliti gaya bahasa } \\
\text { terjemahan teks bahasa sasaran } \\
\text { agar makna terjemahan adalah } \\
\text { selari dengan teks bahasa sumber. } \\
\text { - Olah, ubahsuai dan murnikan }\end{array}$ \\
\hline
\end{tabular}


DOI: https://doi.org/10.47405/mjssh.v6i4.727

- Gaya bahasa yang terlalu mudah atau pendek juga tidak menunjukkan kemantapan ayat dalam menyampaikan mesej.

- Tiada kepelbagaian istilah yang menyebabkan gaya bahasa menjadi kaku.

- Ketidakmampuan dalam menghasilkan terjemahan teks sasaran dengan gaya bahasa yang sesuai dan tepat mengikut laras dan gaya bahasa sastera, budaya dan ekonomi.

\section{Perkataan Budaya}

\section{Kohesi dan} Koheren

Isu-isu Lain
- Perkataan budaya yang tidak dibekalkan dengan peluasan kata sebagai penjelasan kepada makna yang dimaksudkan.

- Kesalahan terjemahan perkataan budaya seperti terjemahan kata seru.

- Pemadanan perkataan budaya yang tidak bersesuaian dengan budaya teks sasaran.

- Penanda wacana yang tidak menepati teks bahasa sumber dan teks sasaran.

- Aspek kohesi dan koheren tidak dapat diwujudkan kerana terdapat terjemahan kata ganti diri yang kurang tepat.

- Teks sasaran lompong dan tiada kesinambungan antara frasa atau perenggan.

- Teks sasaran kaku. ayat mengikut gaya bahasa yang mudah difahami dalam bahasa sasaran.
- Tambah pengetahuan budaya bahasa sasaran melalui pembacaan, rujukan mengenai budaya yang diamalkan oleh penutur jati bahasa sasaran supaya menghasilkan terjemahan perkataan budaya yang lebih tepat.

- Semak makna padanan yang dibekalkan.

- Sediakan senarai penanda wacana dan kata hubung yang pelbagai bagi bahasa sasaran untuk digunakan dalam terjemahan serta membuat semakan terjemahan bagi memastikan ketepatan dan kesinambungan ayat terjemahan.

- Kuasai bahasa sumber dan bahasa sasaran dengan baik supaya dapat memindahkan maklumat teks sumber ke dalam bahasa sasaran dengan tepat dan menyeluruh.

- Melakukan penstrukturan linguistik yang melibatkan penanda wacana, ayat, perkataan dan makna teks.

- Penggunaan terjemahan di Google Translate memerlukan proses semakan dan kemas kini.

- Pastikan setiap terminologi yang digunakan menepati konteks.

- Pastikan padanan yang diberikan menepati konteks latar budaya 
kepincangan ayat dan makna.

Selain itu, dua orang pakar rujuk jemputan dalam kajian ini turut menyuarakan pandangan terhadap isu terjemahan Arab-Melayu melalui aplikasi Google Translate. Secara umumnya, kedua-duanya menyokong bahawa hasil terjemahan GT daripada bahasa Arab ke bahasa Melayu mempunyai kekurangan dan kelemahan yang perlu ditangani semasa proses penyuntingan. Selain itu, mereka turut mengutarakan beberapa aspek tumpuan yang harus dilihat dengan teliti oleh penterjemah atau penyunting seperti di dalam Jadual 2.

Jadual 2: Pandangan Pakar Terhadap Isu Hasil Terjemahan GT

\section{Aspek tumpuan}

Makna Denotasi/Frasa Kata

Nama/Frasa Kata Nama Khas

Semantik

Frasa

Pengembangan Ayat

(Expansion)

Perkataan Budaya
Google Translate tidak boleh menterjemah secara tepat.

Hasil terjemahan Google Translate bermasalah dari sudut semantik

Google Translate tidak berupaya menterjemah sesuatu yang bersifat idhofah dengan tepat

Contoh: ما أحلى akan diterjemahkan Google Translate sebagai "bagaimana manis" dan bukan diterjemahkan sebagai "alangkah indahnya".

Google Translate tidak boleh terjemah dengan tepat frasa idiomatik.

Contoh: "انتقل إلى رحمة الله "akan diterjemahkan Google Translate sebagai "pergi ke rahmat Allah".

Contoh: "مع السلامة" akan diterjemahkan Google Translate sebagai "dengan keselamatan".

Contoh: "لا شكر على الواجب" akan diterjemahkan Google Translate sebagai "tidak terima kasih kerana tugas".

Apabila terjemahan daripada Bahasa Arab ke Bahasa Melayu, hasil terjemahan akan menjadi lebih panjang daripada teks sumber.

Terjemahan satu perkataan kepada banyak makna tidak dapat diterjemahkan dengan tepat.

Tidak mampu terjemah ungkapan istilah.

Peribahasa, metafora, hiperbola, makna implisit, makna kiasan dan makna tersirat tidak boleh diterjemahkan oleh Google Translate.

Terjemahan tidak dapat dilakukan dengan sempurna bagi perkataan yang sama tetapi mempunyai makna yang berbeza 
Kata Jamak

Kekeliruan Tanda Baris

Partikel

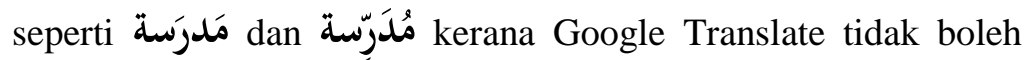
mengesan baris perkataan yang dikehendaki

Google Translate tidak dapat menghasilkan terjemahan yang tepat terhadap kata jamak.

Contoh: الجامعات, hasil terjemahan Google Translate adalah bersifat mufrad (1) iaitu universiti dan bukan universiti-universiti.

Contoh: مِتت متأخرا akan diterjemahkan Google Translate sebagai "tumbuh terlambat". Hal ini berikutan Google Translate telah

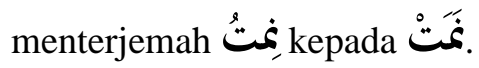

Contoh: مع akan diterjemahkan Google Translate sebagai "dengan" sedangkan makna sebenarnya adalah "walaupun".

\section{Perbincangan Kajian}

Daripada maklumat yang dapat dilihat dalam Jadual 1 dan 2, disimpulkan bahawa teks hasil terjemahan GT daripada bahasa Arab ke bahasa Melayu sememangnya perlu kepada proses penyuntingan, pemurnian dan penstrukturan semula terhadap aspek-aspek tertentu dalam teks tersebut. Di sini penulis merumuskan bahawa terdapat empat aspek utama dalam proses penyuntingan yang perlu dititikberatkan oleh penterjemah sekiranya berhadapan dengan teks hasil terjemahan e-Translasi Arab-Melayu. Aspek-aspek tersebut dan kupasannya adalah seperti berikut:

\section{Perkataan dan frasa}

Adakalanya GT tidak dapat memberikan padanan tepat kepada perkataan dan istilah daripada bahasa Arab ke bahasa Melayu, terutamanya apabila melibatkan perkataan budaya. Hal ini kerana perkataan budaya adalah khusus kepada sesebuah masyarakat dan penggunaannya mungkin berbeza antara satu bBahasa dengan bahasa yang lain.

GT juga dilihat tidak dapat menyampaikan maksud frasa tertentu dengan tepat, malah adakalanya menyimpang daripada makna asal, terutamanya frasa idiomatik yang lazimnya mempunyai makna konotasi berbeza daripada makna literal frasa tersebut. Selain itu, contoh perkataan yang mungkin menghadapi masalah apabila diterjemahkan oleh GT ialah perkataan berbentuk polisemi (satu kata yang mempunyai makna lebih dari satu.) atau himonim (dua kata yang bentuk penulisan dan pengucapannya sama tetapi ertinya berbeza). Di sini, GT adakalanya tidak dapat memberikan padanan yang tepat dengan konteks ayat. Ini juga menunjukkan kepada kita bahawa GT tidak dapat menyampaikan makna dari sudut semantik dengan tepat apabila berhadapan dengan perkataan dan frasa tertentu.

Dalam konteks ini, penterjemah perlu melihat secara teliti penggunaan perkataan, istilah atau frasa sama ada dalam teks sumber mahu pun teks sasaran dengan mengambil kira konteks penggunaannya dalam ayat. Selain itu, penterjemah perlu meneliti sama ada terjemahan perkataan atau frasa tersebut adalah tepat dan digunakan secara meluas dalam teks sasaran.

\section{Ayat}

Dalam aspek ini, tumpuan diberikan kepada aspek struktur ayat dan gaya bahasa. Dari sudut struktur ayat, kebanyakan ayat dalam teks Bahasa Arab adalah panjang dan lazimnya dihubungkan dengan kata 
hubung ' $w a$ ' (dan) apabila diterjemahkan melalui GT. Hal ini menyebabkan berlakunya pengulangan 'dan' dalam satu ayat yang sama dalam teks sasaran. Dalam konteks ini, penterjemah perlu membuat anjakan dalam struktur ayat tersebut dengan memendekkan atau memisahkan ayat-ayat panjang kepada unit ayat yang lebih kecil.

Terdapat juga struktur ayat yang tidak diterjemahkan dengan tepat dan kelihatan kaku, mungkin kerana hasil terjemahan GT tersebut berbentuk literal. Ia memberi kesan kepada cara penggunaan bahasa dalam teks sasaran atau gaya bahasa secara tidak langsung. Ini akan menghasilkan teks sasaran yang 'berbau terjemahan', iaitu salah satu ciri yang menunjukkan bahawa terjemahan tersebut tidak mencapai kualiti yang baik.

Penterjemah disarankan agar memfokuskan makna teks dan bukannya terikat dengan struktur ayat dalam teks sumber. Selain itu, pendekatan komunikatif boleh diguna pakai supaya teks sasaran tampak lebih natural, sejadi dan mudah difahami oleh pembaca. Perhatian juga perlu diberikan terhadap penggunaan gaya bahasa yang sesuai mengikut konteks, situasi atau laras bahasa teks sumber dalam teks sasaran.

\section{Teks}

Antara perkara penting yang sering dilihat dalam teks ialah kohesi dan koheren. Hasil kajian menunjukkan bahawa hasil terjemahan GT tidak dapat mewujudkan kesinambungan yang baik antara unsur teks sepenuhnya, Dalam erti kata lain, kohesi dan koheren tidak dapat direalisasikan ekoran terdapat terjemahan ganti nama yang tidak tepat, selain kedapatan penggunaan penanda wacana yang tidak tepat dalam teks sasaran.

Dalam hal ini, penterjemah harus meneliti setiap unsur teks dengan teliti semasa penyuntingan dan pemurnian hasil terjemahan GT dilakukan. Bahasa Arab banyak sekali menggunakan kata ganti nama sehingga adakalanya agak sukar bagi penterjemah untuk mencari rujukan kata ganti nama, terutamanya rujukan anafora (rujukan pada unsur sebelumnya). Oleh itu, amat penting bagi penterjemah mengetahui jalan cerita atau watak dalam teks untuk menangani masalah ini.

Selain itu, kita dapati bahawa teks bahasa sasaran (Bahasa Melayu) selalunya akan menjadi lebih panjang daripada teks bahasa Arab. Hal ini mungkin tidak dapat dielakkan. Namun, penterjemah tidak boleh seratus peratus mengikut gaya penulisan teks Arab yang lazimnya memisahkan satu ayat dengan yang lain dengan hanya menggunakan tanda koma dan penanda wacana ' $w a$ ', iaitu 'dan'. Dalam hal ini, penterjemah boleh mengolah ayat-ayat panjang menjadi lebih pendek dan menggunakan penanda wacana yang pelbagai dan sesuai.

\section{Tatabahasa}

Dari aspek tatabahasa, sistem linguistik bahasa Arab dan bahasa Melayu mungkin mempunyai perbezaan ketara dalam sesetengah keadaan, sebagai contoh: Bahasa Arab mempunyai dua binaan struktur ayat iaitu jumlah fic liyyah (ayat verbal / kata kerja) dan jumlah ismiyyah (ayat nominal / kata nama), manakala Bahasa Melayu hanya mempunyai binaan ayat nominal. Penggunaan partikel dalam bahasa Arab juga pelbagai dan terjemahannya melalui GT atau e-Translasi lain mungkin tidak dapat membekalkan maksud yang menepati sistem tatabahasa Melayu. Begitu juga dengan penggunaan kata jamak dan perkataan lain yang melibatkan aspek linguistik khusus dalam Bahasa Arab, sebagai contoh aspek morfologi seperti yang dinyatakan dalam Jadual 2.

Dalam isu ini, penterjemah seharusnya mahir dalam selok belok sistem tatabahasa Melayu dan tidak terikat dengan sistem tatabahasa Arab. Penterjemah juga boleh mulakan terjemahan menggunakan terjemahan ayat yang menggunakan tatabahasa asas yang kemudiannya ditambah baik secara berperingkat bagi mengelakkan kesalahan terjemahan ayat kompleks yang menggunakan tatabahasa yang lebih kompleks. Selain itu, lakukan analisis hubungan tatabahasa iaitu kata-kata yang membawa mesej dan makna seperti ungkapan lisan, istilah ungkapan yang menjadi norma bahasa sasaran untuk 
menghasilkan makna linguistik, makna rujukan dan makna emosi seperti yang dicadangkan oleh subjek kajian.

Selain daripada aspek-aspek yang diketengahkan di atas, penterjemah juga perlu memastikan kandungan mesej yang diterjemahkan melalui GT adalah tepat dan tidak menyimpang daripada kehendak asal teks sumber. Semua aspek harus diberi perhatian secara menyeluruh apabila melakukan penyuntingan terhadap hasil terjemahan e-Translasi untuk mengelakkan kekeliruan atau ketaksaan dalam memahami mesej sebenar teks sumber.

\section{Kesimpulan}

Secara umumnya, e-Translasi berperanan untuk menjadikan proses terjemahan lebih produktif dan efektif. Namun, kita juga tidak dapat menyangkal akan kekurangannya. Hasil terjemahan e-Translasi lebih bersifat literal dan adakalanya tidak dapat memberikan padanan yang tepat dan sesuai dalam teks sasaran. Banyak kajian lepas telah membuktikan hal ini, oleh itu penterjemah tidak boleh bergantung sepenuhnya kepada teks terjemahan yang dihasilkan melalui e-Translasi tanpa menyunting, memurni mahu pun menstrukturkan semula teks tersebut.

Pelbagai aspek perlu diberi perhatian semasa menyunting teks terjemahan e-Translasi Arab-Melayu. Dapatan kajian menunjukkan bahawa terdapat beberapa aspek dalam teks terjemahan Google Translate (GT) yang perlu dilihat dan diteliti seperti penggunaan perkataan dan frasa, binaan struktur ayat dan kesinambungan ayat atau perenggan dalam teks sasaran. Selain itu, perbezaan antara sistem tatabahasa antara bahasa Arab dengan bahasa Melayu merupakan salah satu perkara yang perlu juga diambil perhatian oleh penterjemah atau penyunting semasa proses penyuntingan dilakukan. Ketepatan dari aspek pemindahan mesej kandungan teks sumber ke teks sasaran juga tidak kurang pentingnya untuk memastikan agar tiada makna teks sumber yang disalah tafsir sehingga berlaku kehilangan atau penyelewengan makna.

Proses penyuntingan dianggap sangat penting dalam memastikan mutu dan kualiti hasil terjemahan terjamin dalam mana-mana kerja penterjemahan. Apatah lagi jika teks sumber diterjemahkan melalui aplikasi e-Translasi yang telah diketahui mempunyai kekurangan tertentu. Dalam proses ini, kepakaran manusia tetap diperlukan untuk menangani apa jua masalah yang timbul daripada teks yang dihasilkan melalui e-Translasi. Oleh itu, penterjemah atau penyunting harus memiliki kemahiran menterjemah dan pengetahuan yang luas dalam kedua-dua bahasa kerana perkara ini menjadi kriteria asas dalam amalan penterjemahan. Ini juga menunjukkan bahawa gabungan antara e-Translasi dan terjemahan manusia masih dianggap suatu kemestian sehingga hari ini. Apa yang pasti, ketepatan teks terjemahan hanya akan dapat dicapai melalui sumbangan penterjemahan mesin yang mempunyai keistimewaan tersendiri dan penterjemahan manusia yang berkebolehan dalam memperbaiki mutu penterjemahan mesin melalui pasca-suntingan seperti yang dikaji oleh penyelidik dalam kajian ini.

\section{Penghargaan}

Setinggi-tinggi penghargaan kepada pihak Pusat Pengurusan Penyelidikan USIM kerana memberi dana bagi menjalankan kajian ini melalui Geran Penyelidikan USIM (kod projek: PPPI/FPBU/0118/051000/16718).

\section{Rujukan}

Bernardini, S. (2001). Think-aloud Protocols in Translation Research: Achievement, limits, future prospects. Target Online, 13(2), 241-263.

Eftekhary, A. A., \& Aminizadeh, S. (2012). Investigating the Use of Thinking Aloud Protocols in Translation of Literary Texts. Theory and Practice in Language Studies, 2(5), 1039-1047. 
Ericsson, K. A., and Simon, H. A. (1993). Protocol Analysis: Verbal Reports as Data. Cambridge, MA: MIT Press.

Goh, S.S. (2013). Proses penterjemahan. Dalam Haslina Haroon \& Hasuria Che Omar (Eds.), Asas Terjemahan dan Interpretasi. Pulau Pinang: Penerbit Universiti Sains Malaysia, hlm 19-34.

Khadijah, S dan Maheram, A. (2013). Penterjemahan Frasa Al-Idafah Arab-Melayu Menggunakan Google Translate Translating Phrases of Al-Idafah of Arab-Malay Using Google Translate. Islamiyyat The International Journal of Islamic Studies, 35(2), 101-108.

Kussmaul, P. \& Tirkkonen-Condit, S. (1995). Think-Aloud Protocol Analysis in Translation Studies. TTR: traduction, terminologie, rédaction, 8(1), 177-199.

Nida, E \& Taber, C. (1969). The Theory and Practice of Translation. Leiden, Netherlands: E. J. Brill.

Nord, C. (1997/2001). Translating as a Purposeful Activity: Functionalist Approaches Explained. Manchester: St. Jerome.

Nur Faezah Mohd Ayob. (2015). Perbandingan antara Terjemahan Manusia dengan Terjemahan Mesin dalam Penterjemahan Teks Teknikal. Tesis Sarjana tidak diterbitkan, Universiti Putra Malaysia.

Smith, A. (2014). Think aloud protocols: Viable for teaching, learning and professional development in interpreting. The International Journal for Translation \& Interpreting Research, 6(1), 128143.

Wan Rose Eliza, A.R. (2013). Penggunaan peralatan dan teknologi dalam penterjemahan. Dalam Haslina Haroon \& Hasuria Che Omar (Eds.), Asas Terjemahan Dan Interpretasi. Pulau Pinang: Penerbit Universiti Sains Malaysia.

Widdowson, H.G. (2013) Penterjemahan (terj Haslina Haroon). Kuala Lumpur: Institut Terjemahan \& Buku Malaysia.

Zaleha, A.R. (2004). Protokol Pemikiran Verbal dalam Pembelajaran bahasa Melayu. Tesis Sarjana tidak diterbitkan, Universiti Putra Malaysia. 